\title{
El comercio de México y su relación con Canadá en el TLCAN
}

DOI: $10.32870 /$ mycp.v3i10.102

Agustina Rodríguez A.*

$\mathrm{E}$ 1 Tratado de Libre Comercio de América del Norte (TLCAN) se da en el marco de la globalización de los mercados y busca desaparecer las barreras arancelarias y no arancelarias del comercio internacional. Así, los mercados se han ido integrando en forma paulatina hasta llegar a elevados grados de adhesión como en el caso de la Unión Europea. Otros ejemplos más comprehensivos de integración constituyen los países que forman el Foro de Cooperación Económica de Asia Pacífico (APEC), cuyos integrantes abrirán sus mercados en dos etapas; en primer lugar, los países industrializados en 2010 y en segundo lugar, los países en desarrollo en 2020. Y la iniciativa de los países como es el Acuerdo de Libre Comercio de las Américas (ALCA).

Por otra parte, podemos observar que no solamente en bloques o grupos de países se busca la integración económica global, los países por separado buscan acuerdos o tratados estratégicos bilaterales con el objeto de no quedar fuera de esta modalidad globalizadora. Incluso países que no habían participado hasta ahora en tratados de libre comercio bilaterales como es el caso de algunos países de Asia Pacífico; en la actualidad ya se habla de negociaciones entre Japón y Corea, Japón y Singapur, Japón y México, México y Singapur. Por su parte, México ha entrado de lleno a esta corriente liberalizadora, ya que es el país que más tratados de libre comercio ha firmado, aunque el TLCAN ha recibido mayor atención por haber sido integrado por países con fuerte asimetría económica.

Estados Unidos históricamente ha sido el principal socio comercial de México. En 1937 los volúmenes comerciales de México hacia Estados Unidos ya se mantenían elevados,

* Investigadora del Departamento de Estudios del Pacífico de la Universidad de Guadalajara. respecto a los demás países, pues representaban 56 por ciento de las exportaciones totales mexicanas. En el decenio de los noventa, México ha exportado en promedio 85 por ciento a Estados Unidos, mostrando siempre una tendencia ascendente, alcanzando 88 por ciento en 1999. En el caso de las importaciones, han tenido un similar comportamiento. En 1939, el 58 por ciento provenían de Estados Unidos, en 1944 este porcentaje se elevó a 90 por ciento y en el período de los noventa han mantenido un promedio de 73 por ciento.

\section{Evolución reciente del comercio con Estados Unidos}

Los primeros indicios de la apertura comercial mexicana se dan en 1977, con la eliminación gradual de los permisos previos de importación. Con esta iniciativa ya se vislumbraba una política de apertura comercial, aunque no se hablaba abiertamente de ello. Posteriormente, en 1979, Estados Unidos como buen previsior del actuar de sus socios comerciales y en aras de proteger su industria impidiendo caer en un déficit comercial, emitió la Ley de Acuerdos Comerciales, por la cual se permitió cobrar un impuesto compensatorio a las mercancías que ingresaran al territorio estadounidense y que fueran apoyadas con subsidios en el país de origen. En el caso de México se aplicaron impuestos, avalados por esta ley, a los productos del acero, textiles, vidrio y productos de la construcción; en ese momento el país no contaba con los instrumentos suficientes para defenderse de las acusaciones de que era objeto por parte de Estados Unidos. Para poder hacerlo, este país debería ser miembro de algún organismo internacional ante el cual pudiera demostrar que no practicaba el comercio desleal. 
Esta situación, juntamente con otros desajustes en la economía, como fue la crisis por la disminución en el precio del petróleo y la acumulación de la deuda externa, así como las presiones por parte de Estados Unidos para propiciar una mayor apertura comercial, indujeron un giro importante en la economía mexicana. Así, se implementaron nuevas políticas comerciales y México pasó de ser un país proteccionista a una economía abierta, disminuyendo las barreras arancelarias y no arancelarias. En 1983 se reducen las tarifas de aranceles con un tope máximo de 20 por ciento ad valorem, además de la eliminación de los permisos previos a la importación. Para complementar lo anterior, en 1984 se estableció el Programa Nacional de Fomento Integral al Comercio Exterior (PRONAFICE). En ese mismo año (1984), Estados Unidos reforzaba la ley emitida en 1979, solamente que ahora con el nombre de Ley de Comercio y Aranceles, requiriendo una mayor apertura de sus socios en lo que respecta a mercancías y capitales estadounidenses.

En 1985 México y Estados Unidos firmaron un memorándum de entendimiento comercial sobre derechos e impuestos compensatorios, que tuvo como

finalidad comprometer a México a no aplicar subsidios a las exportaciones protegiendo así la industria norteamericana. Por otro lado, estaban las cuotas "voluntarias", que consistían en que los países que comerciaran con Estados Unidos se autoimpusieran un tope a las exportaciones de mercancías que se dirigieran a ese país. En México se hicieron efectivos en las exportaciones del acero; con el acuerdo multifibras, se fijaron restricciones a los textiles, lo que ocasionó una limitante para los productores nacionales de ropa y telas; a los productos agropecuarios se les aplicaron restricciones no arancelarias como son las reglas fitosanitarias. En 1986 México ingresa oficialmente al Acuerdo General de Aranceles y Comercio (GATT); de esta forma, Estados Unidos tendría que demostrar que México hacía uso de prácticas desleales en el comercio para que procedieran las sanciones impuestas.

A finales de 1988 México firmó un acuerdo sobre inversiones estadounidenses y, en 1989, emite la Ley de Inversión Extranjera, por la que se acuerda otorgar todo tipo de facilidades para penetrar en todas las áreas productivas, incluso las consideradas como estratégicas, por ejemplo la petroquímica, las telecomunicaciones y la industria siderúrgica.

El 12 de agosto de 1992 concluyeron las negociaciones del TLCAN, según el documento oficial, los tres países se comprometieron a promover el empleo y el crecimiento económico mediante la expansión del comercio y de las oportunidades de inversión en la zona, además de que dicho tratado aumentaría la competitividad internacional de las empresas mexicanas, canadienses y norteamericanas. De igual forma, se comprometieron a proteger el medio ambiente, promover el desarrollo sostenible y proteger los derechos laborales.

Para el logro de lo antes expuesto se fijaron los siguientes objetivos específicos: eliminar barreras al comercio, promover condiciones para una competencia justa, incrementar las oportunidades de inversión, establecer procedimientos efectivos para la aplicación del tratado y la solución de controversias, fomentar la cooperación trilateral, regional y multilateral. Esto se lograría mediante el cumplimiento de los principios y reglas del tratado, como trato nacional, nación más favorecida y aplicación de las reglas de origen. 
México y Estados Unidos se comprometieron a eliminar de inmediato sus barreras no arancelarias mediante su conversión al sistema arancel-cuota o, en algunos casos, simplemente aranceles y la eliminación de los aranceles en una amplia gama de productos.

Las barreras arancelarias entre México y Estados Unidos se eliminarán en un período no mayor a diez años después de la entrada en vigor del TLCAN, salvo los aranceles de ciertos productos extremadamente sensibles, entre los que se encuentran el maíz y el frijol para México y para Estados Unidos el jugo de naranja y el azúcar, productos que disminuirán su protección de manera gradual en un lapso de cinco años adicionales a los fijados en el tratado para la desgravación en la mayoría de los productos. La política comercial que ha seguido México desde los primeros indicios de apertura al comercio ha respondido, en muchas ocasiones, a lineamientos impuestos por los intereses extranjeros, en este caso de Estados Unidos.

Las cifras oficiales macroeconómicas indican un incremento en el poder adquisitivo de la población; sin embargo, la concentración del ingreso se ha dado en muy pocos sectores de la población. Los volúmenes del comercio se han incrementado, pero se concentran en empresas transnacionales provenientes principalmente de EU y algunas de Canadá. De esta manera, se busca solucionar el problema del desempleo en México y se opta por atraer inversión extranjera que requiera de la mano de obra nacional.

\section{Canadá y el comercio exterior}

Canadá no difiere mucho de México en cuanto a los elevados volúmenes de comercio que se intercambian con Estados Unidos, ya que también para Canadá ese país es su principal socio comercial. En 1989, Canadá y Estados Unidos implementaron un Acuerdo de Libre Comercio (FTA, por sus siglas en inglés), bajo el cual se eliminarán en un período de diez años todas la barreras arancelarias entre los dos países. Sin embargo, en enero de 1994 se firmó el TLCAN, que ahora extiende el área de libre comercio a México.

Canadá es un país que depende mucho del comercio exterior; 43 por ciento del PIB canadiense se origina en las exportaciones de bienes y servicios, de las cuales un porcentaje muy alto va hacia Estados Unidos. En el período 1970-1979 las exportaciones a Estados Unidos representaron 68.6 por ciento, manteniendo un ritmo ascendente al alcanzar 85 por ciento en 1999. Otro socio importante para Canadá es la Unión Europea, región que ha experimentado una disminución gradual en su importancia como mercado, al pasar de 11.3 por ciento en los setenta a 5 por ciento en 1999 (ver cuadro 1). En tercer lugar se encuentra Japón, que también mantiene una tendencia a la baja, llegando a representar 2.6 por ciento de las exportaciones canadienses. En 1999 los principales productos de exportación canadienses (26 por ciento respecto al total ) son maquinaria y equipo (23.6 por ciento). Las

\section{Cuadro 1}

Canadá: Principales mercados de exportación, 1970-1999

(porcentajes)

\begin{tabular}{lrrrrrr}
\hline & $1970-1979$ & $1980-1989$ & $1990-1999$ & 1997 & 1998 & 1999 \\
\hline & & & & & & \\
EU & 68.6 & 73.7 & 79.8 & 80.5 & 83.6 & 85.9 \\
U. Europea & 11.3 & 7.9 & 6.3 & 5.7 & 5.5 & 5 \\
Japón & 5.9 & 5.4 & 4.2 & 4.1 & 3 & 2.6 \\
Resto del mundo & 14.2 & 13 & 9.7 & 9.8 & 7.9 & 6.5 \\
\hline
\end{tabular}

Fuente: Department of Foreigns Affairs and International Trade, First Annual Report on Canada's State of Trade, Second Edition, june 2000. 


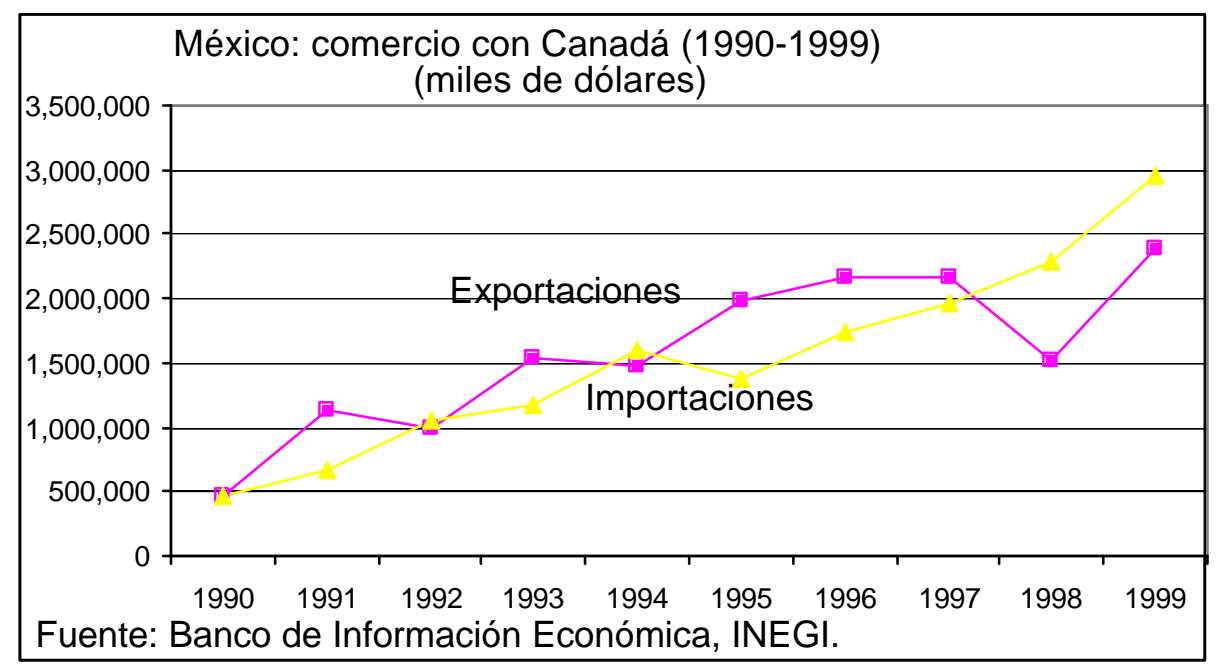

importaciones de Canadá están compuestas principalmente por maquinaria y equipo, que representan 33.1 por ciento.

Versiones oficiales respecto a la economía de Canadá hacen notar un comportamiento favorable en las variables macroeconómicas del país, resaltando el incremento en los flujos comerciales. El éxito observado en dichas variables se le atribuye a los efectos que ha ocasionado el TLCAN. Sin embargo, los grandes volúmenes del comercio canadiense siguen orientados al mercado estadounidense y no así a su otro socio en el TLCAN, México. Aunque las exportaciones de México a Canadá registran un incremento en el volumen del comercio (en 1991 se exportaron 1125 millones de dólares y en 1999 este volumen ascendió a 2311 millones de dólares), el incremento de México a Estados Unidos ha sido mayor (en 1991 se exportaron 33912 millones de dólares y en 1999 éstas se incrementaron a 120610 millones de dólares), lo que significa que la proporción de las exportaciones hacia Estados Unidos se incrementó de 79 por ciento del total en 1991 a 88 por ciento en 1999. De 1991 a 1997 México había mantenido un superávit comercial con Canadá, con excepción de 1995 y 1992, pero después de 1997 se observa un déficit muy marcado para México que amenaza con incrementarse (ver gráfica). Los principales productos que México exporta a Canadá son automóviles de turismo y transporte, computadoras, motores y aceites crudos de petróleo. En conjunto, este grupo representó 66 por ciento de las exportaciones mexicanas a Canadá en 1999 (ver cuadro 2).

En el marco del TLCAN quedó asentado que México y Canadá eliminarían barreras arancelarias y no arancelarias a su comercio agropecuario, con excepción de las que se aplican a productos lácteos, a los avícolas, al huevo y al azúcar. Canadá eximió inmediatamente a México de las restricciones a la importación de trigo y cebada así como sus derivados, carne de res, ternera y margarina. Canadá y México eliminarían de manera inmediata o en un período máximo de cinco años, las tasas arancelarias que aplican a la mayoría de los productos hortícolas y frutícolas, y en diez años para los productos restantes. No obstante el comercio entre estos dos países, no se da en forma prioritaria en estos productos sino en los que ya se mencionaban anteriormente.

\section{Inversión extranjera directa en los países de América del Norte}

Estados Unidos es el principal inversionista en México y Canadá. Los sectores que han recibido mayor inversión norteamericana en Canadá son: finanzas y seguros, energía y metales y maquinaria y equipo de transporte. Por su parte, la inversión extranjera directa (IED) en Canadá en 1999 incrementó en 14 miles de millones de dólares, (de 24.4 mil millones de dólares en 1998 ascendió a 38.4 miles de millones de dólares en 1999), como resultado principalmente de la llegada a Canadá de empresas o inversionistas estadounidenses, firmas que se dedican al giro de ventas y adquisiciones.

Por su parte, México en materia de inversión se comprometió a permitir de inmediato, a los inversionistas de países miembros del TLCAN, la participación de hasta 100 por ciento 


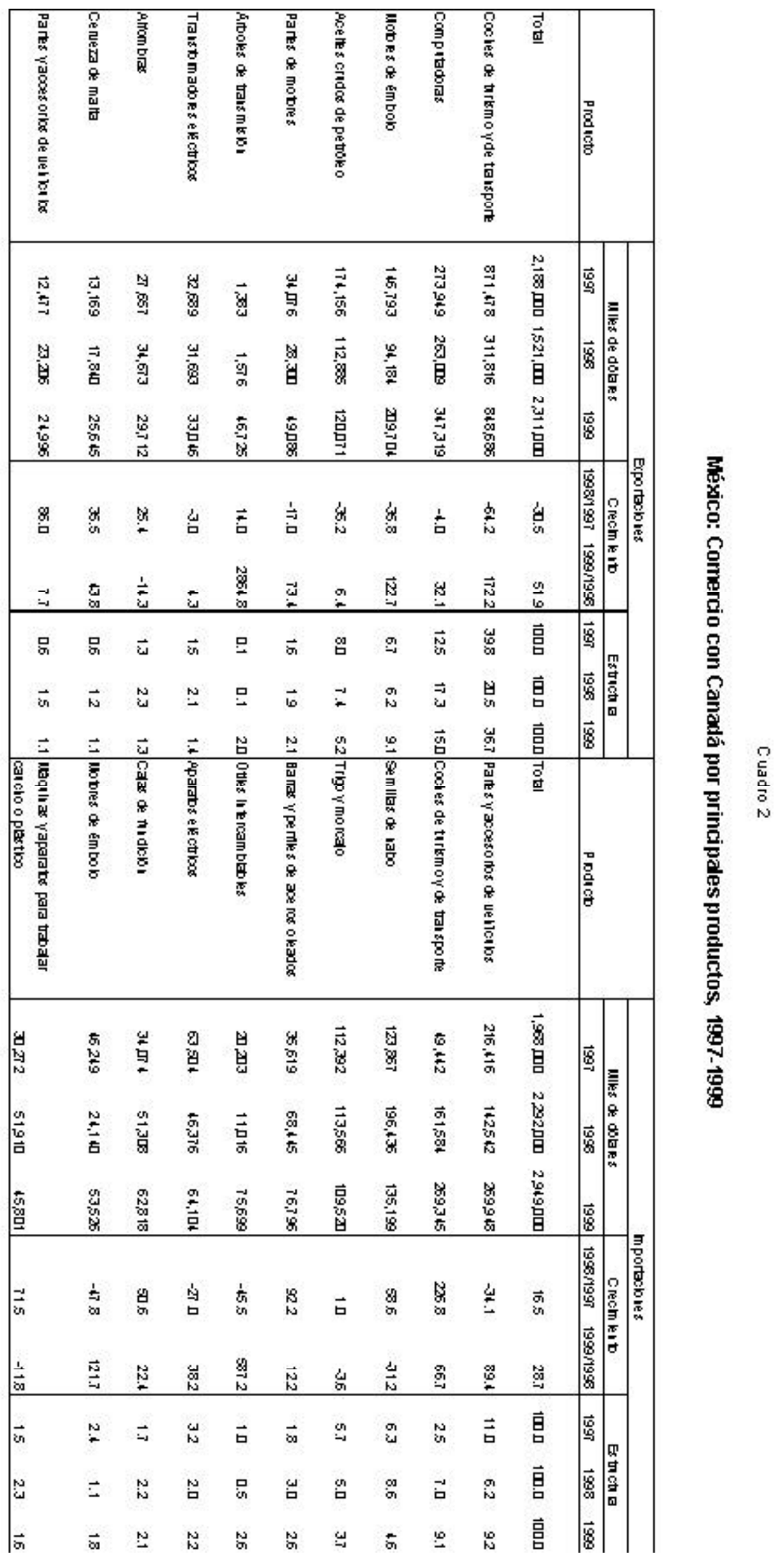


en las empresas consideradas "proveedores nacionales" de auto, partes y hasta 49 por ciento en otras empresas, incrementándose a 100 por ciento al término de cinco años.

Según cifras oficiales mexicanas, las principales ventajas del TLCAN han sido la llegada al país de la inversión extranjera directa $\mathrm{y}$ el incremento en el volumen comercial. Al igual que sucede en Canadá, el mayor porcentaje de inversión en México proviene de Estados Unidos. En el sector que se concentra mayor inversión es en la industria manufacturera, específicamente en la actividad maquiladora, a las cuales se les ha dado todo tipo de facilidades para su instalación en México, con la única consigna de la creación de empleos en el país, cuyos gastos de la industria instalada en México son primordialmente sueldos, salarios y prestaciones que perciben los trabajadores. El actuar de estas empresas ha sido muy cuestionado, ya que no da origen a la transferencia de tecnología ni existen proveedoras nacionales que tengan como fin abastecer a las transnacionales. De acuerdo con el origen de la IED, su mayor porcentaje se concentra en Estados Unidos, quien ha mostrado mayor actividad tanto en comercio como en la IED en los países miembros del TLCAN.

\section{Inversión en México Proveniente de los países de América del Norte}

Al cierre de marzo de 2000, se localizaban en México 12557 empresas con inversión proveniente de América del Norte, lo cual representa 66.8 por ciento del total de sociedades de inversión foránea establecidas en el país (suman en total 18809 empresas). Los inversionistas norteamericanos participan en forma mayoritaria en el capital social de 10831 sociedades representando 86.3 por ciento, Canadá solamente participa con 13.7 por ciento.

Las empresas con inversión proveniente de América del Norte se ubican principalmente en el sector manufacturero, donde se concentra 35 por ciento del total, en el sector servicios se ubica 34.8 por ciento y en el comercio 21.2 por ciento.

Cuadro 3

Distribución sectorial de la inversión materializada en México de los países de América del Norte, 1994-2000/*

Porcentajes

\begin{tabular}{|c|c|c|c|}
\hline & Estados Unidos & Canadá & Total/1 \\
\hline Acumulada del período (miles de dólares) & $35,131,220.9$ & $2,343,091.7$ & $37,474,312.6$ \\
\hline Total & 100 & 100 & 100 \\
\hline Agropecuario & 0.43 & 0.03 & 0.41 \\
\hline Minería y extracción & 0.11 & 9.34 & 0.69 \\
\hline Industria manufacturera & 60.87 & 60.03 & 60.82 \\
\hline Electricidad y agua & 0.08 & 0.00 & 0.08 \\
\hline Construcción & 1.18 & 0.38 & 1.13 \\
\hline Comercio & 13.73 & 5.73 & 13.23 \\
\hline Transportes y comunicaciones & 4.69 & 0.00 & 4.40 \\
\hline Servicios financieros & 10.64 & 23.51 & 11.45 \\
\hline Otros servicios/2 & 8.26 & 0.97 & 7.80 \\
\hline
\end{tabular}

*/Para el período 1994-1998, la inversión extranjera directa (IED) se integra con los montos notificados al Registro Nacional de Inversiones Extranjeras (RNIE), más las importaciones de activo fijo realizadas por sociedades maquiladoras. A partir de 1999 se incluyen además los conceptos de nuevas inversiones, reinversión de utilidades y cuentas entre compañías, que se han notificado al RNIE.

Cabe mencionar que esta información no incluye toda la inversión realizada por inversionistras de América del Norte, debido a que no se incluyen las inversiones que realizan las empresas de esa región a través de sus filiales en otros países, pues el país de la inversión se clasifica con base en la nacionalidad del inversionista extranjero y no al origen primario de los recursos.

$1 /$ Notificada al 31 de marzo de 2000.

2/Servicios comunales y sociales; hoteles y restaurantes; profesionales, técnicos y personales. Incluye los a la agricultura, ganadería, construcción, transportes, financieros y comercio.

Fuente: SECOFI. Dirección General de Inversión Extranjera. 
En lo que respecta a los montos de IED, se mantienen como los principales inversionistas Canadá y Estados Unidos, este último con 75.4 por ciento seguidos por la Unión Europea con 17.4 por ciento. La Inversión de América del Norte ubicada en México se concentra en la industria manufacturera la cual representa 60 por ciento en promedio en el período 1994-2000 (ver cuadro 3), y en 199972.8 por ciento.

Canadá ocupa el sexto lugar como país inversionista en México con una IED acumulada de 2343.1 millones de dólares entre enero de 1994 y marzo de 2000; de la cual, 60 por ciento se destinó al sector manufacturero, 24.5 por ciento a servicios y el resto a otros sectores. La industria manufacturera concentra el mayor porcentaje de IED en la industria automotriz (278 empresas), 27 empresas en la industria farmacéutica y en menor número, fabricación de maquinaria y equipo, accesorios eléctricos, fabricación y ensamble de equipos electrónicos y confección de prendas de vestir. Por otro lado, 236 empresas en el sector comercio (que ocupa el segundo lugar después de la industria manufacturera) integran el comercio de servicios no alimentarios y comercio de manufacturas. En tercer lugar en minería y extracción con 223 empresas.

\section{Comentarios finales}

¿En realidad se han alcanzado los objetivos propuestos en el TLCAN? En lo que pudimos apreciar, la relación comercial de México y Estados Unidos ya mantenía altos porcentajes en volumen de comercio, aun cuando no se había firmado el tratado de libre comercio. En lo que respecta a Canadá y México, los volúmenes que se intercambian no son relevantes, por lo que no se observa una diversificación en el mercado en ninguno de los tres países, sino por el contrario se siguen conservando los mismos patrones. ¿A caso se obedece a las fuerzas de consorcios internacionales, que son los que marcan la pauta del comercio?

Como podemos apreciar Estados Unidos ha dictado una amplia gama de leyes y reglas con el único fin de proteger la industria estadounidense que así lo requiera. Mientras que México, al abrirse al comercio en varias direcciones, ha provocado que la industria nacional haya quedado desamparada no tomando en cuenta que ésta se compone principalmente por empresas micro, pequeñas y medianas, las cuales no tienen capacidad para convertirse en exportadoras de la noche a la mañana. Mientras tanto, Estados Unidos sigue pugnando por una mayor apertura con sus principales socios comerciales.

Quizá no hemos sabido orientar las importaciones en aras de equipar la industria nacional con tecnología de punta, para alentar las exportaciones de productos nacionales que incluyan alto valor agregado en los productos que se venden en el exterior.

Mucho se habla de las condiciones desiguales entre los miembros del TLCAN; cuando se firmó se manejó oficialmente que por ser desiguales los países podrían complementarse y obtener ganancias como resultado del comercio entre ellos. Según datos estadísticos, esta complementariedad no se ha dado todavía, por ejemplo, no se observan grandes volúmenes de productos agrícolas mexicanos a Estados Unidos o a Canadá, considerando las barreras que sobre este tipo de productos se siguen manteniendo por parte de Estados Unidos principalmente.

\section{Fuentes}

Department of Foreigns Affairs and International Trade, First Annual Report on Canad's State of Trade, second edition, june 2000. Secretaría de Comercio y Fomento Industrial (SECOFI), Subsecretaría de Negociaciones Comerciales Internacionales, Dirección General de Inversión Extranjera, Inversión de América del Norte en México, marzo de 2000. Instituto Nacional de Estadística, Geografía e Informática (INEGI), estadísticas del Banco de Información Económica, 1999. Gitli Eduardo y Gómez Chiñas Carlos, "La política comercial de México y el Entendimiento con Estados Unidos", Análisis Económico, Universidad Autómona Metropolitana, Unidad Azcapotzalco, División de Ciencias Sociales y Humanidades, vol. IV, Núm. 6, enero-junio de 1995, p. 205226. 